\title{
Identification, Characterization and Quantification of Elastomeric/Plastomeric Waste for Sustainable Waste Minimization
}

\author{
${ }^{1}$ Kajal Yadav, ${ }^{2}$ Sangita and ${ }^{3}$ A.Chandra \\ ${ }^{1}$ Indian Institute of Technology, Delhi, India \\ ${ }^{2}$ Pavement Engineering and Materials, Central Road Research Institute \\ Mathura Road, N.D. 110020, India \\ ${ }^{3}$ Centre for Energy Studies, Indian Institute of Technology, Delhi, India
}

\begin{abstract}
The present study focuses on the importance of characterization of waste/post consumer polymers. In recent years sophisticated instrumental techniques played an important role in identification and characterization of polymers. Advances in computer techniques have been combined with analytical instruments to give analytical speed, resolution and minimal sample requirements unimagined a few years ago. The present study deals with the development of modified binder formulations from plastomer and elastomer type waste with an aim to minimize nonbiodegradable the post consumer polymer waste as well as environmental hazard, to meet this objective ten different samples have been picked up from several kinds of waste so as to cover different categories of polymeric waste from the domestic, industrial as well as medical waste. The samples were characterized using thermal characterization techniques like DSC (differential scanning calorimetry) and TGA (thermo gravimetric analysis). The melting and oxidative degradation behavior of polymer waste helped in sustainable waste management through developing the various modified bitumen formulations of commercial importance for highway industry. Modified binder formulations were initially characterized as per the relevant standards (code of practice) to ascertaining their suitability for above said application. The physical properties of modified binders are within the specified limits. Marshall stability, indirect tensile strength and creep modulus behaviour have been evaluated and discussed in this study to prove their dual benefits like waste minimization and suitability of such binders to be used for durable roads.
\end{abstract}

Key words: Identification and characterization of polymers, plastomer and elastomer type waste, indirect tensile strength, creep modulus behaviour

\section{INTRODUCTION}

Developing countries such as India are undergoing a massive migration of their population from rural to urban centres. India will have more than 40 per cent, i.e. over 400 million people, clustered in cities over the next thirty years ${ }^{[1]}$. Modern urban living brings on the problem of waste, which increases in quantity and changes in composition with each passing day ${ }^{[2]}$.

The creation of non-decaying waste materials of municipal solid waste has resulted in a waste disposal crisis. India is already facing plastic disposal problems of the kind faced in the developed world, which is fast running out of space for landfills to control nonbiodegradable waste. One conventional solution to this crisis lies in recycling waste in to useful products. According to manufacturers, almost all these types of waste can be recycled up to four or five times. However, the quality of the recyclate deteriorates and additives or virgin material are added to give it strength. Consumption, linked to per capita income, has a strong relationship with waste generation. As per capita income rises, more savings are spent on goods and services. India will probably see a rise in waste generation from less than 40,000 metric tones per year to over 125,000 metric tones by the year 2030 .

The new Municipal Solid Waste Management Rules 2000, which came into effect from January 2004, fail even to manage waste in a cyclic process. First, it does not address mechanisms which will be needed for promoting recycling, or waste minimization. Secondly, there is no provision for any public participation ${ }^{[3]}$. Waste management still is a linear system of collection and disposal, creating health and environmental hazards ${ }^{[4]}$.

However, new and expensive technologies are being pushed to deal with our urban waste problem, ignoring their environmental and social implications. For example, the United States has not been able to install a new incinerator for the past five years, while costs for burning garbage have escalated astronomically with rising environmental standards in Europe ${ }^{[5]}$. 
Waste minimization includes the series of steps from identification, recycling, reduce, reuse elimination etc. Thus, identification and characterization achieve the first rank among waste minimization steps. The environmental and the socio-economic impacts of waste management can be significant and wide-ranging; thus waste management is central to the sustainable development agenda. The following were the techniques adopted for identification and characterization of polymeric waste. Thermal analysis comprises a group of instrumental analytical techniques which are particularly powerful tools for the identification and characterization of polymer materials. Essentially a thermal analytical method is one which follows the change in property in a sample whilst that sample is subjected to a predetermined temperature regime.

\section{MATERIALS AND METHODS}

Two types of waste materials were considered for sustainable waste management. 1) Plastomeric type e.g. polythene bags from packaging industry \& used glucose bottles segregated from bio-medical waste. 2)Elastomeric type e.g. waste rubber powder from automobile industry. The sieve analysis results of the powder obtained from these elastomers indicated 98$100 \%$ passing through 600 micron sieve and $5 \%$ passing through 150 micron. The binder used to accommodate these wastes is $80 / 100$ grade bitumen conforming to Bureau of Indian standards specifications with the penetration 86 and softening point $45^{\circ} \mathrm{C}$.

Plastic wastes were characterized using thermal techniques prior to incorporating them with the road binder. The sample weights taken to run the test for glucose bottles, polyethylene bags, waste tire rubber and gasket were1.0, 3.0, 9.6 and $15.0 \mathrm{mg}$, respectively and the heating rate was kept $5^{\circ} \mathrm{C} \min ^{-1}$. Thermo gravimetric analysis (TGA) was run using the inert atmosphere and a heating rate of $20^{\circ} \mathrm{C} \mathrm{min}^{-1}$. A Sample weight, $6.412 \mathrm{mg}$ (glucose bottle), $1.117 \mathrm{mg}$ (polyethylene bags), $5.848 \mathrm{mg}$ (waste tire rubber) and $8.320 \mathrm{mg}$ (gasket) was taken to run the test.

\section{RESULTS AND DISCUSSION}

The results of DSC are given in Table 1 . The results of TGA are given in Table 2 .

Various formulations of commercial importance were prepared by adding varying quantity of individual plastomer $(5 \%)$ or elastomer $(10 \%)$ to $80 / 100$ penetration grade bitumen under specified mixing time and temperature using a high speed stirrer. For example the blending temperature was kept $20-30^{\circ} \mathrm{C}$ higher than the melting temperature of plastomers (as obtained from DSC results of different plastomeric waste samples) and minimum $50^{\circ} \mathrm{C}$ lower than the initial decomposition temperature (as obtained from thermogravimetric analysis).

Table 1: DSC test results obtained on differential scanning calorimeter

\begin{tabular}{llll}
\hline Sample & Onset Tm & Peak Tm & Completion of melting \\
Glucose bottle & $103.78^{\circ} \mathrm{C}$ & $106.3^{\circ} \mathrm{C}$ & $112.1^{\circ} \mathrm{C}$ \\
Polythene bags & $121.4^{\circ} \mathrm{C}$ & $125.15^{\circ} \mathrm{C}$ & $128.2^{\circ} \mathrm{C}$ \\
Gasket & Melting & - & - \\
Scrap rubber powder & - do- & - & - \\
Parag milk pouch & 123.06 & 122.152 & 125.086 \\
Mother dairy milk pouch & 108.105 & 115.083 & 124.956 \\
Amorphous glass & 90 & 115 & 120.23 \\
Si-glove & 89.5 & 116.494 & 139.886 \\
Pepsi bottle & 239.48 & 248.78 & 253.72 \\
Hard glass & 154.37 & 166.505 & 170.183 \\
\hline
\end{tabular}

Table 2: Results of thermo gravimetric analysis of waste samples

\begin{tabular}{|c|c|c|c|c|c|}
\hline S.No. & Sample & Initial decomposition temp. ${ }^{\circ} \mathrm{C}$ & $\operatorname{Tmax} .{ }^{\circ} \mathrm{C}$ & Final decomposition temp. ${ }^{\circ} \mathrm{C}$ & Residue at $450^{\circ} \mathrm{C}$ \\
\hline 1. & Glucose bottle & 260 & 440 & 540 & $20 \%$ \\
\hline 2. & Polythene bags & 240 & 440 & 500 & $37.5 \%$ \\
\hline 3. & Gasket & 220 & 520 & 796 & $85 \%$ \\
\hline 4. & Waste tire rubber & 210 & 500 & 780 & $60 \%$ \\
\hline 5. & Parag milk pouch & 240 & 420 & 500 & $15 \%$ \\
\hline 6. & Mother dairy milk pouch & 250 & 440 & 520 & $10 \%$ \\
\hline 7. & Amorphous glass & 300 & 450 & 540 & $20 \%$ \\
\hline 8. & Si-gloves & 260 & 400 & 680 & $10 \%$ \\
\hline 9. & Pepsi bottles & 340 & 460 & 620 & $20 \%$ \\
\hline 10. & Hard glass & 250 & 430 & 460 & $22 \%$ \\
\hline
\end{tabular}

Table 3: Blending time/ Temperature for different modifiers to be used for preparing modified binder formulations

\begin{tabular}{llcl}
\hline $\begin{array}{l}\text { Designation of modified } \\
\text { binder formulations }\end{array}$ & Modifier & Blending Temp. & $\begin{array}{l}\text { Blending time } \\
\text { (minutes) }\end{array}$ \\
\hline A & polythene bags & $150 \pm 5^{\circ} \mathrm{C}$ & $40-60$ \\
B & Waste glucose bottles & $140 \pm 5^{\circ} \mathrm{C}$ & $40-60$ \\
C & Waste tire rubber powder and gasket powder & $160 \pm 5^{\circ} \mathrm{C}$ & $40-60$ \\
D & Mother dairy \& Parag milk pouches & $140 \pm 5^{\circ} \mathrm{C}$ & $40-60$ \\
E & Hard glass & $170 \pm 5^{\circ} \mathrm{C}$ & $40-60$ \\
\hline
\end{tabular}


Am. J. Environ. Sci., 1 (3): 202-205, 2005

Table 4A: $\quad$ Physical properties of the modified bitumen and specified Limits as per IS: 15462:2004

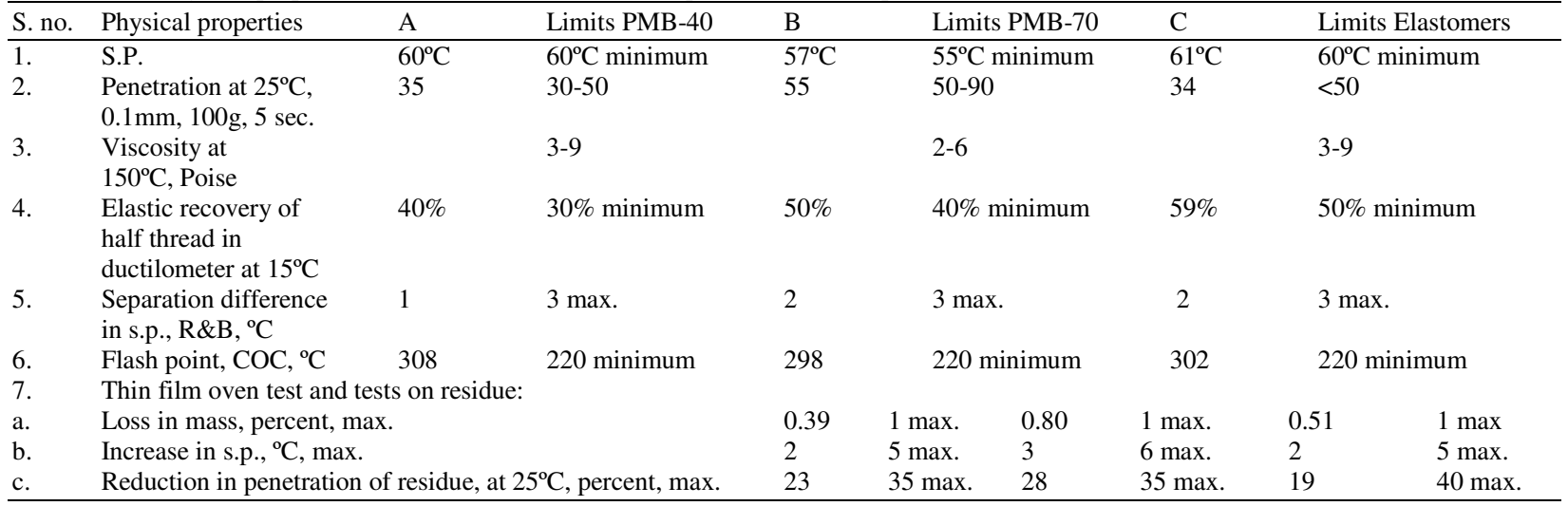

Table 4B: Design of asphalt concrete mixes

\begin{tabular}{|c|c|c|c|c|c|}
\hline S.no. & Physical properties & $\mathrm{D}$ & Limits PMB-120 & $\mathrm{E}$ & Limits PMB-70 \\
\hline 1. & S.P. & $57^{\circ} \mathrm{C}$ & $50^{\circ} \mathrm{C}$ minimum & $56^{\circ} \mathrm{C}$ & $55^{\circ} \mathrm{C}$ minimum \\
\hline 2. & Penetration at $25^{\circ} \mathrm{C}, 0.1 \mathrm{~mm}, 100 \mathrm{~g}, 5 \mathrm{sec}$ & 89.6 & $90-150$ & 52 & $50-90$ \\
\hline 3. & Viscosity at $150^{\circ} \mathrm{C}$, Poise & & $1-3$ & & $2-6$ \\
\hline 4. & $\begin{array}{l}\text { Elastic recovery of half thread in ductilometer at } 15^{\circ} \mathrm{C} \text {, } \\
\text { minimum }\end{array}$ & $55 \%$ & $50 \%$ & $35 \%$ & $40 \%$ minimum \\
\hline 5. & Separation difference in s.p., $\mathrm{R} \& \mathrm{~B},{ }^{\circ} \mathrm{C}$ & 1 max. & 3 max. & 2 max. & 3 max. \\
\hline 6. & Flash point, $\mathrm{COC},{ }^{\circ} \mathrm{C}$ & & & & 220 minimum \\
\hline 7. & Thin film oven test and tests on residue: & & & & \\
\hline a. & Loss in mass, percent, max. & 0.42 & 1.0 & 0.71 & 1 \\
\hline b. & Increase in s.p., ${ }^{\circ} \mathrm{C}, \max$. & 3 & 7 & 2 & 6 \\
\hline c. & $\begin{array}{l}\text { Reduction in penetration of residue, at } 25^{\circ} \mathrm{C} \text {, percent, } \\
\text { max. }\end{array}$ & 22 & 35 & 25 & 35 \\
\hline
\end{tabular}

Table 5: Physical Properties of Aggregates

\begin{tabular}{llcr}
\hline S.no. & Property & Value in $\%$ & Limits as per morth \\
\hline 1. & Aggregate Impact Value & 18 & Max. 24\% \\
2. & Flakiness + Elongation Index & 28 & Max. 30\% \\
3. & Water Absorption & 0.3 & Max. 2\% \\
\hline
\end{tabular}

Table 6: Engineering properties of mixes

\begin{tabular}{lcccc}
\hline Sample & Marshall stability, $\mathrm{Kg}, 60^{\circ} \mathrm{C}$ & Marshall quotient, $\mathrm{Kg} \mathrm{m}^{-1}$ & Flow value, $\mathrm{mm}, 60^{\circ} \mathrm{C}$ & Indirect tensile strength \\
\hline A & 1687 & 511.21 & 3.3 & 10.21 \\
B & 1150 & 302.6 & 3.8 & 8.0 \\
C & 1465 & 505.17 & 2.9 & 10.5 \\
D & 1600 & 516.12 & 3.1 & 10.25 \\
E & 1150 & 425.92 & 2.7 & 8.2 \\
$80 / 100$ & 1055 & 277.6 & 3.8 & 7.8 \\
\hline
\end{tabular}

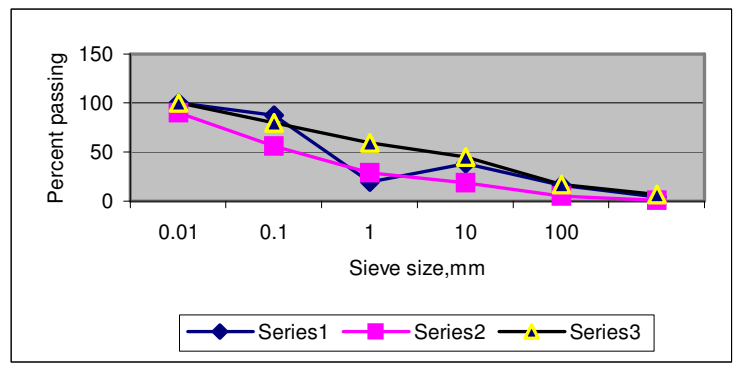

Fig. 1: Asphalt-concrete gradation

Elastomeric wastes were blended with bitumen at $160^{\circ} \mathrm{C}$ well below their initial decomposition temperatures which were 210 and $220^{\circ} \mathrm{C}$, respectively for tire rubber and gasket powder. The designation of modified binders and relevant blending parameters are given in Table 3.

Formulations A\&B contain 5\% modifier to the weight of bitumen. Formulation C contains $10 \%$ rubber $\&$ gasket powder to the weight of bitumen. Formulation D contains $10 \%$ mother dairy and parag milk pouches to the weight of bitumen. Formulation E contains $5 \%$ of hard glass to the weight of bitumen.

Physical properties of the modified bitumen formulations are given below which met the limits as specified in IS: $15462: 2004^{[6]}$ (Table 4A and B).

The physical properties of Delhi quartzite aggregates used in this study are given in Table 5. The Marshall method of the mix design as per ASTM 
D1559 was used for determination of the optimum binder content. Aggregate gradation as indicated in Fig. 1 was used. Marshall Specimens were also cast at optimum binder content (5.6\% by wt. of aggregates) using modified binder formulations. Their properties are given in Table 6 . The test results of indirect tensile strength obtained as per ASTM 4123 are also given in Table 6.

\section{CONCLUSION}

Based on the characterization data of modifiers and modified formulations the following conclusions can be drawn:

1. The data obtained through characterization technique is helpful in selecting the optimum blending conditions so that dispersion of waste is uniform and no overheating is done. For example the blending temperature is generally kept $20-30^{\circ} \mathrm{C}$ higher than its melting point and $50^{\circ} \mathrm{C}$ lower than its initial decomposition temperatures. DSC results of plastomers indicated that these particular samples of waste has mainly LDPE of melting point $125.15^{\circ} \mathrm{C}$ and LLDPE of melting point $106.3^{\circ} \mathrm{C}$. TGA results indicated that the initial decomposition temperature was 240 and $260^{\circ} \mathrm{C}$ in case of plastomeric waste and $210 \& 220^{\circ} \mathrm{C}$ in case of elastomeric waste, showing that there are negligible emissions below this temperature limit. The blending temperatures were selected keeping in view the melting and degradation behaviour of different waste samples. Thus Characterization of a material (to be used for any kind of development) is the backbone for a process or product developed. Characteristics of a material reflect from the beginning till end in one or the other way.

2. The various binder formulations developed using these waste materials have shown the improved physical properties and met the requirements of plastomer and elastomer modified bitumen to be used for road construction. It can be concluded with the help of various formulations that $5 \%$ of individual plastomer and $10 \%$ of elastomer can be incorporated in per kilogram of conventional binder.
3. Therefore disposing them in to bituminous binder will result in dual benefit:

(a) Minimization of waste in environment.

(b) Development of modified bitumen of commercial importance.

4. Bituminous mixes containing $5 \%$ of plastomer modified binder and $10 \%$ of elastomer modified binder were found to have improved stability and indirect tensile strength.

5. Significant improvement in Marshall stability has been found in case where plastomers e.g. polythene bags, milk pouches and mother dairy pouches and elastomers e.g. tire rubber powder, gasket powder were used. However in case of glucose bottles and hard glasses (made of polypropylene) stability was marginally improved. 6 . Indirect tensile strength of bituminous mixes was significantly improved in case of modified binder containing $5 \%$ of glucose bottles or $5 \%$ of hard glasses made of polypropylene. A two fold improvement was obtained in indirect tensile strength of modified bituminous mixes containing gasket/tire rubber powder or polythene bags in comparison to the conventional mixes.

\section{ACKNOWLEDGEMENT}

The authors are thankful to the Director, Central Road Research Institute, New Delhi for his kind permission to publish this research.

\section{REFERENCES}

1. UN, Washington, D.C. 1995.

2. Patel. Almitra H. Using city compost for urban farming in India.

3. University of Agricultural Sciences, Bangalore, All-India co-ordinated research project on dryland agriculture, quoted in Down To Earth, 15th November, 2001.

4. Characterization of MSW in United States: 1992. Update, Executive summary, Report no. EPA/5305-92-0.

5. WWW.Indiatogether.org

6. Bureau of Indian standards, 2004. Indian Standard Polymer and rubber Modified BitumenSpecification. 